\title{
LOS DESAFÍOS DE LA SEGURIDAD SOCIAL EN EL SIGLO XXI
}

\author{
Héctor Humeres Noguer* \\ Universidad de Chile
}

\begin{abstract}
RESUMEN: El autor expone los actuales desafíos por los que atraviesa el Sistema de Seguridad Social. Para ello, pasa revista a los antecedentes históricos de la Seguridad Social, su actual configuración, y los instrumentos de la OIT que orientan a los sistemas nacionales de seguridad social. Termina con una propuesta de solución a las situaciones que afectan a las cinco principales ramas del Sistema de Seguridad Social, esto es, la Salud, las Pensiones, la protección de Riesgos Profesionales, la Protección del Desempleo y las Prestaciones familiares.
\end{abstract}

Palabras clave: Sistema de Seguridad Social, ley, sistemas de reparto, sistemas de capitalización individual - reforma.

ABSTRACT: The author discusses the current challenges being experienced by the Social Security System. To this end, he reviews the historical background of Social Security, its current configuration, and the ILO instruments that guide the national social security systems. It ends with a proposed solution to the situations involving the five main branches of the Social Security System, i.e., Health, Pensions, Professional Risk Protection, Unemployment Protection and Family Benefits.

Key words: Social security system, law, repartition systems, individual capitalization systems, reform.

\section{DESCRIPCIÓN CONCEPTUAL}

La Seguridad Social, con el contenido que el concepto actualmente posee, tiene una historia reciente, pues se trata de una disciplina cuya evolución conceptual está situada en pleno siglo XX.

No es fácil anticipar un concepto definitivo sobre lo que es la Seguridad Social, dada la amplitud y la gama de sus intereses, y de su evolución tan persistentemente dinámica; no obstante, nos atrevemos a consignar la definición que de ella dio la Comisión de Expertos que, el año 1964, elaboraron el denominado "Informe sobre la reforma de la Seguridad Social chilena", y que reza así: "La Seguridad Social -en su concepto integral y moderno- es la rama de la política socio-económica de un país, por la cual la comunidad protege a sus miembros, asegurándoles condiciones de vida, salud y trabajo socialmente suficientes, a fin de lograr mejor productividad, más progreso y mayor bienestar comunes"'.

Este concepto nos parece que tiene el mérito de ser muy simple en su forma, pero de una gran profundidad en sus alcances; podrá ser discutido con relación a estos últimos, pero ello de-

Abogado. Profesor titular de Derecho del Trabajo, Facultad de Derecho, Universidad de Chile. Director del Departamento de Derecho del Trabajo y de la Seguridad Social, Facultad de Derecho, Universidad de Chile.

\footnotetext{
1 Esta Comisión fue formada el año 1959 a instancias del Primer Mandatario de la época, don Jorge Alessandri Rodríguez, presidida por el ilustre abogado don Jorge Prat Echaurren e integrada por muchos calificados y diversos especialistas. Asimismo, contó con el apoyo de los mejores técnicos existentes sobre la materia a la fecha en Chile. La Comisión elaboró un total de 13 informes -el último de los cuales contenía los planteamientos sobre cuál, en su concepto, debía ser el nuevo Sistema de Seguridad Social nacional-, los que bajo la forma de dos tomos (en 1.554 páginas) fueron publicados por la Editorial Jurídica de Chile durante los años 1964 y 1965. Se le considera el estudio más amplio y completo efectuado sobre la materia en Chile y, habitualmente, se le conoce bajo el nombre de "Informe Prat", en homenaje a quien liderara tan magna obra.
} 
penderá, finalmente, del juicio que cada cual nos formemos acerca de lo que debe comprender un sistema de esta naturaleza.

No obstante lo anterior, algunas de sus instituciones tienen sus orígenes o antecedentes en épocas históricas remotas.

\section{LOS PRECEDENTES}

Los collegia romanos, que reunían a personas que ejercían un mismo oficio, fueron verdaderas sociedades de socorros mutuos, cubriendo ciertas necesidades, especialmente las derivadas de las enfermedades o muerte de sus miembros; en opinión de algunos autores, sin embargo, la asistencia, salvo en lo relativo a los entierros, fue excepcional en Roma.

Al entrar en decadencia los collegia, algunos de ellos derivaron hacia una especie de cofradías, para dar paso a las diaconías, que fueron sociedades fundadas por los primeros cristianos para la práctica de la caridad cristiana.

En la Baja Edad Media surgen las gildas, instituciones de origen germánico dedicadas a la asistencia mutua y fraternal. En el siglo XII surgen las primeras cofradías como tales, instituciones de asistencia mutua, especialmente para casos de enfermedad y muerte.

A partir de los siglos XIII y XIV surgen las cofradías-gremios, que agrupaban a personas de una misma actividad y que realizaban, por una parte, sus funciones de origen gremial, $y$, por otra, cumplían funciones de asistencia y previsión propias de las cofradías.

En el siglo XVI aparecen las hermandades de socorros, las cuales se acercan más a la noción de un seguro, constituyendo el antecedente de las mutualidades o sociedades de socorros mutuos, siguiendo las cofradías encaminadas a la protección de los más humildes y débiles.

En el siglo XVIII aparecen los montes de piedad o montepíos, especialmente en el sector público-militar; estaban destinados a ocuparse de la supervivencia, y la protección de las viudas y huérfanos.

Todas estas instituciones, en mayor o menor grado, se ocupaban de las actualmente llamadas contingencias sociales, al estallar la Revolución Francesa, a fines del siglo XVIII.

\section{LAS LEYES DE BISMARCK Y SU INFLUENCIA}

A fines del siglo XIX nacen los primeros Seguros Sociales en la Alemania imperial, de carácter obligatorio, merced al empuje y genialidad política de Otto von Bismarck.

El programa de Bismarck fue realizado entre 1883 y 1889, mediante la promulgación de diversas leyes:

- $\quad$ Ley de 15 de junio de 1883, sobre seguro de enfermedad;

- $\quad$ Ley de 16 de julio de 1884, sobre accidentes del trabajo y;

- $\quad$ Ley de 22 de junio de 1889 , sobre seguro de invalidez y vejez

Fueron estos los primeros Seguros Sociales obligatorios, por lo que las posteriores legislaciones dictadas sobre esta materia deben reconocer en mayor o menor medida la influencia de estas leyes.

No obstante, las leyes de Bismarck, en especial la relativa al seguro de enfermedad, fueron combatidas, incluso por trabajadores que se consideraban obligados por el Estado; además, 
perdían una bandera de lucha social, lo cual fue un objetivo político indudable perseguido por el canciller alemán.

Las características fundamentales de estos Seguros Sociales alemanes fueron las siguientes:

a) Las personas protegidas fueron los trabajadores de las industrias con rentas bajas;

b) La indemnización fue proporcional al salario que se dejaba de percibir;

c) Eran seguros obligatorios para las respectivas categorías de trabajadores y;

d) Se financiaban mediante cotizaciones de trabajadores y empleadores.

El sistema alemán fue imitado rápidamente por los demás países europeos. Con posterioridad a la Primera Guerra Mundial, en virtud del Tratado de Versalles, se crea la OIT, organismo que en materia de Seguridad Social ha desarrollado una ardua labor.

En efecto, gracias a sus esfuerzos e influencia, los Seguros Sociales fueron siendo paulatinamente adoptados por los demás países del orbe, lo que permitió ir unificando criterios en una materia que por mucho tiempo estuvo entregada a las acciones que el Estado o algunos particulares de buena voluntad quisieron desarrollar. Toda esta incipiente labor iniciada por Bismarck -a quien, con justicia, podríamos denominar "el Precursor"- representó un esfuerzo muy valioso.

\section{EL INFORME BEVERIDGE}

En el año 1941, durante el curso de la Segunda Guerra Mundial, el Gobierno Británico encomendó a una comisión, presidida por el actuario William Beveridge, el estudio y la formulación de recomendaciones para una reforma del sistema de Seguros Sociales vigente a esa fecha, relacionado especialmente con el tema del desempleo, el que se creía sobrevendría una vez finalizado dicho conflicto bélico. En efecto, se observaba con creciente preocupación que los puestos de trabajo de los hombres que se encontraban en el frente de batalla eran paulatina y crecientemente ocupados por jóvenes y mujeres, lo que ocasionaría, al término de la guerra, un grave problema de cesantía cuando los hombres volviesen del frente.

Dicha comisión confeccionó un informe, conocido como el Informe Beveridge, el que fue presentado a la Cámara de los Comunes en noviembre de 1942. El parlamento británico aprobó con algunas modificaciones las formulaciones propuestas y autorizó al Gobierno para dictar las leyes respectivas, que son las siguientes:

Ley de 15 de junio de 1945, sobre subsidios familiares

Ley de 26 de junio de 1946, sobre accidentes del trabajo;

Ley de $1^{\circ}$ de agosto de 1946, sobre Seguros Sociales;

Ley de 6 de noviembre de 1946, sobre servicio nacional de salud y;

Ley de 13 de mayo de 1948, sobre unificación de los servicios de asistencia y previsión social;

Ley de 5 de julio de 1948, sobre seguros de accidentes del trabajo, servicio de salud y asistencia social

Aun cuando Bismarck y Beveridge vivieron en épocas diversas, ambos pueden ser considerados en sus respectivos ámbitos como los grandes impulsores de esta nueva disciplina. Bismarck en la creación de los Seguros Sociales y Beveridge artífice de la moderna Seguridad Social; por ello a este último se le considera "el Padre" de la Seguridad Social moderna. 
En relación al Informe Beveridge, sus aspectos más relevantes pueden sintetizarse en los siguientes tópicos:

I. Extensión de la Seguridad Social a todos los residentes del país, dividiendo para estos efectos la población en las siguientes categorías:

a) Empleados. Aquellos que trabajan vinculados por un contrato de trabajo;

b) Empresarios. Aquellos que desarrollan una actividad económicamente útil, pero no bajo un contrato de trabajo;

c) Dueñas de casa;

d) Adultos que no tienen ingresos;

e) Niños de hasta 16 años;

f) Ancianos sobre la edad de trabajo.

II. Postulaba que la protección de la Seguridad Social debía extenderse a todas las contingencias sociales, tan sólo con algunas limitaciones; acuñó una frase que señalaba que el sistema debía proteger a las personas "desde la cuna hasta la tumba", la que es de por sí muy ambiciosa y plena de idealismo, pero llena de complejidades de orden económico que dificultan en grado extremo su materialización.

III. Fue partidario de la creación de un sistema nacional de prestaciones familiares.

IV. En lo tocante a los montos de las prestaciones, salvo variaciones derivadas del sexo o del estado civil, estimaba que debían ser iguales para todos los beneficiarios, sin que influyera el nivel de rentas que les servía de fundamento.

V. Proclamó asimismo que el sistema había de proteger a "todos los residentes del país", sin hacer cuestión de su origen o permanencia.

VI. En lo relativo a los aportes pecuniarios al sistema, estimaba que debía ser el mismo monto para todas las personas, salvo variaciones en cuanto al sexo.

VII. Se inclinaba por la "unificación de todas las instituciones de Seguros Sociales en un servicio público único", bajo la tuición de un Ministerio de Seguridad Social, a la par que estimaba indispensable la simplificación de todas las formalidades administrativas; lo expresaba en la frase "una sola libreta, una sola estampilla", como una forma de simbolizar la simplicidad que perseguía.

VIII. En cuanto a la salud, era partidario del establecimiento de un servicio nacional de salud, financiado mediante impuestos, que asegurase a toda la población prestaciones médicas gratuitas en sus fases curativa, preventiva y de rehabilitación.

IX. Finalmente, en lo que hace relación con el empleo, se mostraba decidido partidario de una política de pleno empleo.

\section{EVOLUCIÓN ENTRE LA SEGUNDA MITAD DEL SIGLO XX Y COMIENZOS DEL SIGLO XXI}

A partir del término de la Segunda Guerra Mundial, y coincidiendo con la emisión del Informe Beveridge, se intensificó la preocupación internacional por la Seguridad Social, adoptando una serie de países diversas medidas, fundamentadas muy principalmente en el documento a que se ha hecho referencia, el que alcanzó una notable influencia en los más diversos ámbitos. 
Con ello, prácticamente se dio origen al Derecho Internacional de la Seguridad Social, el cual en la década de los 40 alcanzó niveles de sumo interés.

Dentro de este orden de cosas, es del caso citar los instrumentos internacionales sobre la materia que tuvieron gran influencia. A este respecto, cabe consignar la Carta del Atlántico, de agosto de 1941, la cual hizo expresa mención de la Seguridad Social; la Declaración de Santiago de Chile (1942), enmarcada dentro de la Primera Conferencia Interamericana de Seguridad Social, la que contiene declaraciones de mucha trascendencia; la Declaración de Filadelfia (EE. UU., 1944), la cual ya aprobó "recomendaciones", las que posteriormente (1952) dieron base a la emisión del Convenio No 102 sobre Seguridad Social (norma mínima). Asimismo, debe mencionarse el Acuerdo de la 8 a Conferencia de la OEA, países miembros de la OIT, celebrada en Ottawa (Canadá, 1966), conocido bajo el nombre de Programa de Ottawa, que se destaca por un notable pragmatismo y por la circunstancia de concebir la Seguridad Social como un medio de política social en orden a resguardar una equitativa distribución de la renta del país; la Declaración Universal de los Derechos del Hombre (París, 1948), varios de cuyos artículos (22, 23 y 25) hacen referencia a la Seguridad Social, señalando el derecho a ella de toda persona y la necesaria relación con la dignidad y su armónico desarrollo.

Hoy en día se abren paso nuevas figuras de aseguramiento social, algunas de las cuales han suscitado una viva controversia doctrinaria al interior del sistema; temas tales como la capitalización individual, la administración privada con fines de lucro, las crisis de los sistemas de reparto, etc., en la actualidad provocan encendidas polémicas, cuyo fin no se divisa que suceda en forma pronta.

Algunos sostienen que se hace necesario reformar la Seguridad Social para hacerla sostenible, señalando al efecto que es necesario considerar no sólo las características del Sistema (tales como el nivel y la duración de las prestaciones, la población asegurada, etc.), sino también la división de las responsabilidades.

Expresan al efecto que la Seguridad Social no es exclusivamente un asunto del Estado: las empresas, los sindicatos, los sectores industriales y los individuos, a su vez, tienen un rol que cumplir, y dado que en cierta medida los riesgos sociales son endógenos, habría que ocuparse del Seguro allí donde se pueda influir más directamente sobre el riesgo a fin de mejorar su eficiencia.

Esto puede tener lugar en parte dentro del sistema público; una alternativa sería el traspaso de los mecanismos colectivos a otros más individuales, cuyos ejemplos más notorios son los sistemas de pilares múltiples y las cuentas de ahorro.

En efecto, dichos sistemas implican, principalmente, una nueva división de responsabilidades, tomando en cuenta el aspecto endógeno ya señalado de los riesgos sociales y las consecuencias de los sistemas de vida modernos; de otra parte, implican un mayor número de opciones individuales.

Expresan, asimismo, que cuando se trate de reformar la Seguridad Social, será menester encontrar un equilibrio entre los objetivos o principios en competencia, entre la equidad y la eficiencia, entre la solidaridad y la libertad de elección, y entre los riesgos de carácter moral y la selección adversa, lo que constituye una opción difícil, por cuanto la finalidad de la Seguridad Social no es solamente el proporcionar certeza ante un futuro incierto, sino que forma parte importante de la manera en que organizamos nuestra sociedad ${ }^{2}$.

EINERHAND, Marcel y NeKKers, Geralt. "Modernización de la Seguridad Social: cambio de responsabilidades y opción individual”, en: Revista Internacional de Seguridad Social, vol. 57/3 julio-septiembre, 2004, p. 29. 
En todo caso, no nos cabe duda de que estamos a las puertas del advenimiento de cambios radicales de mucha envergadura, los que serán necesarios para adecuar las estructuras del Sistema de Seguridad Social tal como fueron previstas por Beveridge.

\section{TENDENCIAS EXISTENTES}

En el contexto actual, en el centro de profundas reformas al modelo económico basado en el rol preeminente del Estado, se han venido desarrollando una serie de líneas de acción en los Sistemas de Seguridad Social, en búsqueda de que satisfaga las necesidades crecientes de los actores sociales. En dicha línea del pensamiento, se hace necesario destacar:

a) La gestión de la seguridad Social se ha abierto a la posibilidad de que intervenga la actividad privada, tanto con cómo sin fines de lucro, dando paso así a entidades especializadas.

b) El surgimiento de fuentes de financiamiento diversas a los denominados "Fondos de Reparto", otorgándose así un rol muy importante a las denominadas "Cuentas de Capitalización Individual”, fundadas en el ahorro personal, ya sea que financien una globalidad de prestaciones sociales o bien solamente que cooperen parcialmente con ellas.

c) Un alza creciente de los costos de los Sistemas de Seguridad Social, dado el mayor volumen alcanzados por estos y el perfeccionamiento de los mismos.

d) Un retroceso en el contenido de diversos beneficios de carácter previsional, medida forzada por la falta de mayor respaldo financiero.

e) Un aumento de los cambios tecnológicos, lo que crea una notoria asimetría entre el mercado laboral y el crecimiento demográfico.

f) Las políticas nacionales deben asumir los nuevos desafíos planteados por el aumento de la internacionalización de la economía, fenómenos que repercuten en aspectos tales como la migración y las fórmulas de cobertura, financiamiento y pago de los beneficios de carácter previsional.

Sobre este particular, se señala que deben preocuparse fundamentalmente de los grupos poblacionales que se encuentran en un mayor grado de indefensión social, mencionándose entre ellos a las mujeres, las personas de la tercera edad, los menos de edad, los homosexuales, los indígenas, los trabajadores informales, los trabajadores migrantes y sus familias, y las personas discapacitadas.

\section{LA EXPERIENCIA DE LA UNIÓN EUROPEA}

En el marco de las soluciones a los problemas planteados, quizá uno de los planteamientos que conviene tener presente lo constituyan los esfuerzos realizados por la Unión Europea en relación a esta materia.

Si bien la UE carece de un Sistema de Seguridad Social común propio y uniforme para todos sus Estados miembros, ha optado más bien por la pervivencia de los diferentes sistemas nacionales, pero ha ido estructurando mecanismos de coordinación entre los mismos.

Así, el Tratado de Funcionamiento de la Unión Europea ${ }^{3}$, establece que se adoptarán las medidas necesarias que permitan la libre circulación de los trabajadores migrantes y de sus fami-

Artículo 48 del TFUE. 
lias, creando un sistema que permita "la acumulación de los periodos tomados en consideración por las diversas legislaciones para adquirir y conservar el derecho a las prestaciones sociales y el pago de las prestaciones a las personas que residan en los diferentes estados miembros".

De ello se desprende que no se ha pretendido crear un Sistema de Seguridad Social Único, tanto por razones técnicas (diferentes modelos) como financieras, cobrando así especial importancia, las normas de coordinación aplicables al efecto, entre las que los doctrinarios ${ }^{4}$ destacan aquellas relativas a la no discriminación, la exportación extraterritorial de las prestaciones, la totalización de las cotizaciones, y el prorrateo de las prestaciones.

Lo anotado refleja un considerable esfuerzo de coordinación -facilitado por la existencia de políticas comunes y de una moneda ad hoc- que tiende a no perjudicar a los migrantes, aspecto no menor en el mundo actual. A ello cabe agregar las "Directrices Integradas por Directivas y Orientaciones" generadas para procurar economías con alto nivel de empleo que tengan cohesión social y territorial, dotada de "flexiguridad", los que constituyen instrumentos de incidencia indirecta en pro de la solución de la cuestión planteada.

Pero ello ha de entenderse complementado con la adopción de medidas de orden nacional para ajustar las respectivas legislaciones a las realidades propias de cada miembro de la Unión, buscando el equilibrio de orden financiero y técnico, no pocas de ellas impopulares y que han motivado en los últimos años protestas sociales significativas.

\section{LA EXPERIENCIA DE AMÉRICA LATINA}

En nuestro continente, pletórico de diferencias tanto dentro de nuestros países como en el plano nacional, se ha aplicado -con disimiles resultados, la mayoría insuficientes- un Sistema fundado en las matrices de Beveridge y procurando seguir la ideología de un Estado Bienestar, estructura que, en las últimas décadas se ha visto estremecido por la irrupción de sistemas de financiamiento de otra naturaleza (Cuentas de Ahorro Individual en luego de Fondos de Reparto) y la profusa creación de entidades de Gestión Privada, en lugar de la Pública, en aras de encontrar una adecuada sustentabilidad del sistema.

Estos últimos esquemas cuentan con detractores y partidarios, pero a no dudarlo, ha significado una nueva mirada sobre el problema y su solución; la interacción regional se ha visto obstaculizada por la falta de un acuerdo como el de la Unión Europea, lo que es natural, dada la falta de unicidad tanto política como económica, y con pocas excepciones, radicadas ellas a nivel de acuerdos bilaterales.

Esta situación, discutida tanto a nivel doctrinario como político, presenta un muy disímil panorama, con aplicaciones y contrarreformas en no pocos países; no obstante, existen países que hoy día detentan situaciones estructurales similares (no exentas de problemas), como es el caso de Colombia y Chile.

En efecto, en ambos países ${ }^{5}$ se cuenta desde la década de los 80-90 con un sistema integral, conformado por Sistemas de Pensiones basados en ahorro individual, con solidaridad; Sistemas de Salud con enlaces financieros solidarios y regímenes subsidiados; Sistemas de Protección de

\footnotetext{
Fernández Prol, Francisca. "La Seguridad Social en la Unión Europea”. Ponencia presentada ante el IV Congreso Internacional de Derecho del Trabajo y de la Seguridad Social. Colombia, Bogotá, 2013.

Datos de Banco de Información de los Sistemas de Seguridad Social Iberoamericanos. Organización Iberoamericana de Seguridad Social. Febrero 2012.
} 
Riesgos Profesionales basados en las diversas actividades profesionales y; Servicios Sociales Complementarios basados en programas estatales y municipales.

Existen diferencias entre ambos, pero presentan una matriz similar, no exentas de críticas profundas y reformas recientes o en curso.

Otros países del continente han aplicado reformas similares y no pocas contrarreformas, y algunos, han mantenido la estructura del Estado Bienestar, todo lo cual, hasta ahora, ha impedido estructurar un esquema similar al ya comentado de la Unión Europea.

\section{LA POSICIÓN DE LA OIT. EL CONVENIO 102}

La Organización Internacional del Trabajo ha mostrado, desde muy temprano, una profunda y genuina preocupación por la Seguridad Social; Convenios y Recomendaciones tan tempranas como el Convenio 102, sobre Norma Mínima, de 4 de junio de1952, las Recomendaciones 067 de 1944, sobre la seguridad de los medios de vida, y la 069, de 1944, sobre asistencia médica, instrumentos que constituyen una prueba más que palpable de ello, siendo quizá su hito más señero el ya citado Convenio sobre "Norma Mínima", lo que ha continuado ya en este siglo con la presentación de una serie de trabajos vinculados a la materia, todo lo cual ha culminado en fecha reciente con la aprobación de la Recomendación N²02, sobre "Piso de Protección Social" (Conferencia de junio de 2012).

Existe, pues, una preocupación creciente a nivel mundial por esta materia, muy vinculada a los fenómenos económicos que han aparecido en las últimas décadas, y que han convulsionado a prácticamente todos los países y a sus habitantes.

Fenómenos tales como la creciente globalización, la permanencia de una importante informalidad laboral, el aumento del trabajo independiente, el déficit fiscal creciente, la falencia de muchas economías y otros fenómenos coadyuvantes, han estremecido hasta los cimientos las bases de los sistemas basados en las premisas asentadas por Beveridge, y que la gran mayoría del mundo hizo suyas durante más de cuatro décadas, teniendo como meta arribar al denominado Estado Bienestar, basado en los fondos de reparto, con una profunda solidaridad y procurando redistribuir el ingreso.

Junto a ello se he producido el llamado "fenómeno demográfico", el que implica una fuerte caída en las tasas de natalidad y un aumento espectacular de las expectativas de vida de gran parte de la población mundial, lo que ha venido a incidir fuertemente en las aspiraciones de mejores y mayores beneficios a los que estaban tradicionalmente otorgando los Sistemas, provocándoles graves problemas de financiamiento, cuya solución no ha sido sencilla -generalmente con soluciones por la vía del recorte de beneficios- y que se ha traducido en no pocas convulsiones sociales, inclusive en países muy desarrollados.

Las cifras estadísticas conocidas al respecto acusan una compleja realidad: 
Gráfico 1. 1. Población mundial por gupos de edad, 2000-2050

En miles de mibnes de persona

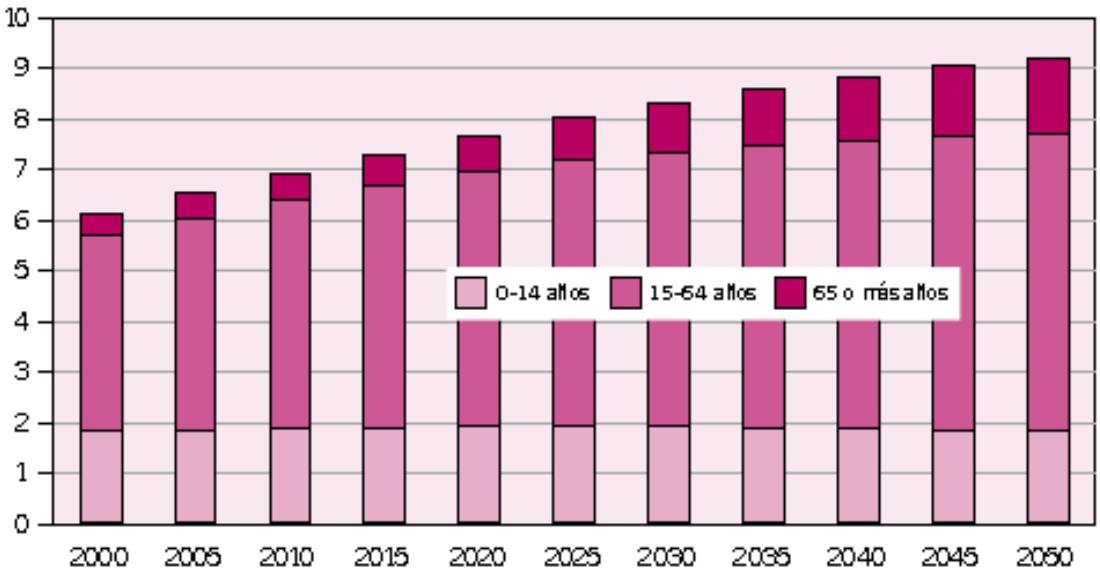

Fuente: Naciones Unidas: Word Population Prospects: The 2006 Revision, División de Población del Departamento de Asuntos Económ icos y Sociales (Nueva York, 2007).

Gráfico 1.11. Tasa de fecundidad total por región geográfica, 1980-2050

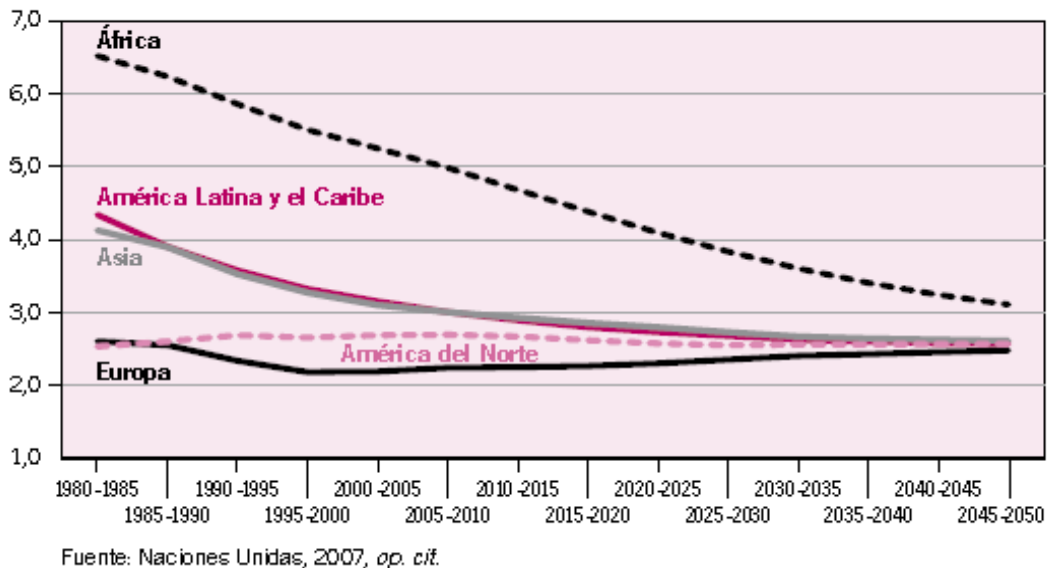


Gráfico 1.6. Población de 60 años o más, por región geográfica, 1980-2050

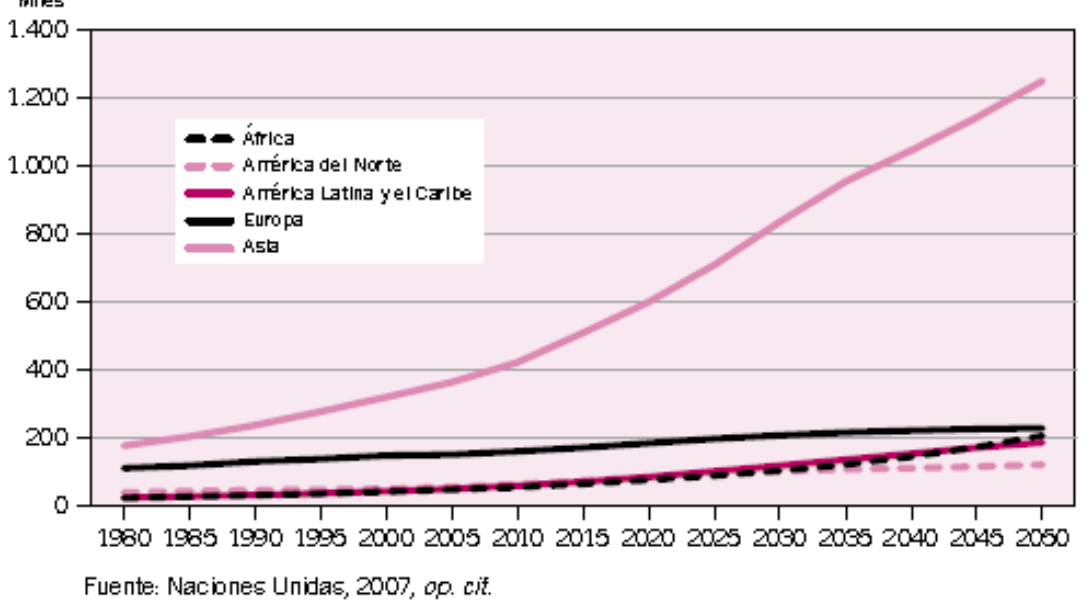

Gráfico 1.16. Número de personas de 80 años o más por zonas de desarrollo, 1980-2050

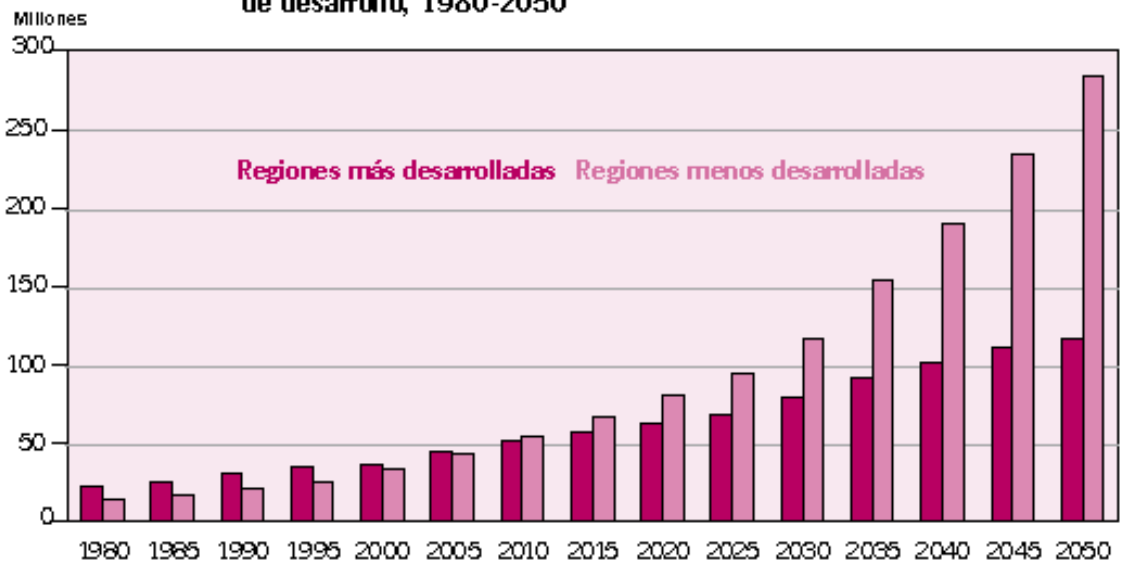

Fuente: Naciones Unidas, 2007, op. ck. 


\section{Gráfico 1.9. Ritmo de envejecimiento del gupo de 80 años o más por región geográfica}

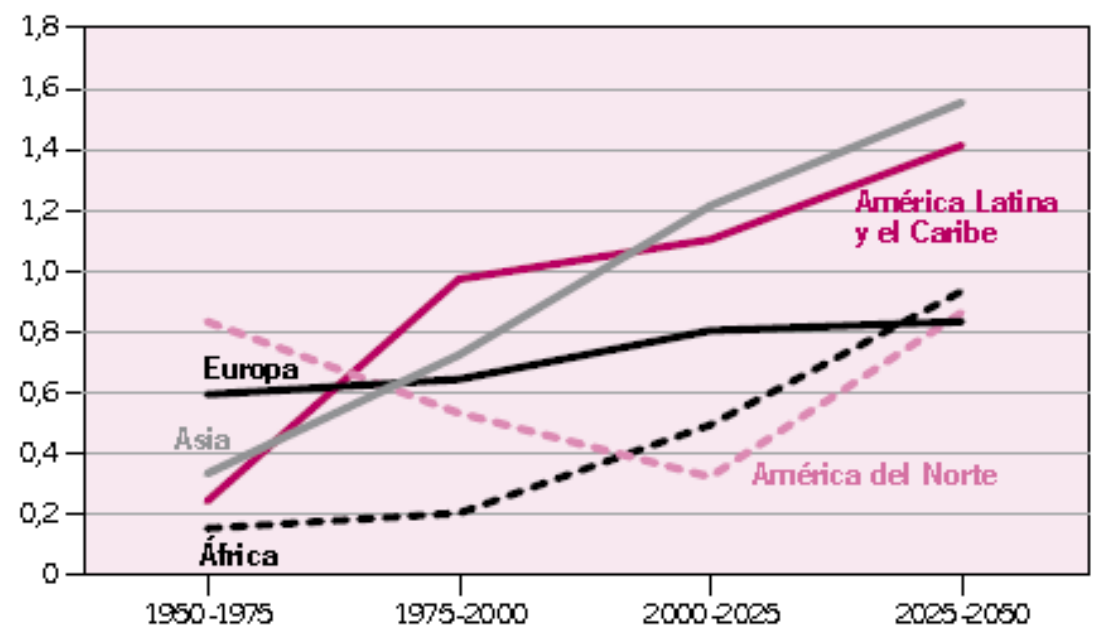

Fuente: Naciones Unidas, 2007, op. cit.

A la vista de estas cifras, y como ya se expresó anteriormente, la preocupación internacional ha sido creciente, no habiendo podido la Organización Internacional del Trabajo sustraerse al debate creado. A este respecto, cabe anotar que ella elaboró en la Conferencia Internacional correspondiente al año $2011^{6}$ un Informe y una Resolución, debiendo destacarse -en lo que nos interesa para esta exposición- que no pueden existir modelos únicos de sistemas de Seguridad Social, sino que cada sociedad debe estructurar la mejor forma de enfrentar sus desafíos, pero ajustándose a determinados parámetros básicos, a saber:

1. Prestaciones seguras y no discriminatorias

2. Regímenes administrados de modo seguro, transparente, costos bajos, y con participación de los interlocutores sociales

3. Deben despertar y asegurar la confianza pública en ellos

Expresa asimismo que los grandes desafíos de todo Sistema serían los siguientes:

a) La extensión de la cobertura;

b) La igualdad de género;

c) El envejecimiento de la población

No obstante, la OIT ha constatado que las premisas ya enunciadas son difíciles de afrontar en forma cabal por la gran mayoría de los países; quizá la prueba más palpable de ello lo constituya el real estancamiento que ha sufrido la ratificación del Convenio 102 sobre "Norma Mínima" de la OIT, el que a la fecha registra un total de 44 ratificaciones a nivel mundial, sobre un universo de 185 países (24\%) que forman parte de la entidad mundial; sus 9 normas clásicas prestacio-

OIT, Ginebra 2002: Un nuevo consenso. 
nales (sobre asistencia médica, prestaciones monetarias en caso de enfermedad, prestaciones de desempleo, prestaciones de vejez, prestaciones en caso de accidentes del trabajo y de enfermedad profesional, prestaciones familiares, prestaciones de maternidad, prestaciones de invalidez, prestaciones de sobrevivientes), las exigencias sobre cálculo de pagos periódicos, e igualdad de trato a los residentes no nacionales, forma de financiamiento a base del Fondo de Reparto, responsabilidad estatal por la administración, han resultado de suyo difíciles y complejas de implementar por muchos países; de hecho, ni Colombia ni Chile se encuentran entre los países que han ratificado el aludido Convenio.

Dicha realidad contrasta con cifras muy decidoras ${ }^{7}$, como las de que cerca de $1.400 \mathrm{mi}-$ llones de personas viven bajo el umbral de la pobreza (fijado en 1,25 dólares al día); que el 75\% de la población carece de una cobertura de Seguridad Social adecuada; que un 20\% apenas de la población mundial en edad de trabajar puede obtener una protección social integral; que la esperanza de vida en los países de bajos ingresos alcanza solo a los 55 años de edad; que 2,3 millones de personas mueren cada año a causa de accidentes y enfermedades relativas al trabajo; que más de 10 millones carecen de acceso a tratamientos médicos; que existen más de 105 millones de trabajadores migrantes, y otras cifras similares que a todos deberían más que preocuparnos.

Por ello es que se ha procedido a elaborar la doctrina del denominado "Piso de Protección Social", el cual fue objeto de discusión y análisis en la última Conferencia Internacional celebrada en Ginebra el pasado mes de junio del año 2012, buscando que con su implantación considerara fenómenos contemporáneos.

\section{EL PISO DE PROTECCIÓN SOCIAL}

Se lo define ${ }^{8}$ como "el conjunto integrado de políticas sociales diseñado para garantizar a todas persona la seguridad de los ingresos y el acceso a los servicios sociales esenciales, prestando especial atención a los grupos vulnerables, y protegiendo y capacitando a las personas a lo largo del ciclo de vida".

El Piso prevé garantías en materia de seguridad básica en lo ingresos. Mediante diversas formas de transferencias sociales, y el acceso universal y asequibilidad a servicios sociales esenciales en los ámbitos de salud, agua y saneamiento, educación, seguridad alimentaria, vivienda y otras esferas definidas en las prioridades nacionales.

El Piso apuesta por la coherencia y coordinación de las diferentes políticas sociales para evitar que los individuos y las familias caigan en la pobreza y la penuria y permanezcan anclados en ella; asimismo, pretende proteger a las personas que no son capaces de obtener unos ingresos decentes a través del trabajo y empoderar a los trabajadores para que aprovechen las oportunidades económicas y encuentren una vía para salir de la pobreza.

Su proceso de aplicación debe ser gradual y progresivo, en función de las prioridades y capacidades nacionales, sobre la base de programas existentes de protección social y mediantes fuentes sostenibles de financiación.

En la construcción de un sistema integral de seguridad social, el Piso debe entenderse como u primer peldaño hacia un nivel más elevado y completo de protección.

Cartilla de "Protección Social para mejorar el trabajo y la vida", OIT.

Junta de Jefes Ejecutivos del Sistema de Naciones Unidas para la Coordinación (JJE) Piso de Protección Social OIT 2011, pág. 9. 
Diversas instancias internacionales le han dado su apoyo a esta iniciativa, debiendo destacarse a su respecto el Pacto Mundial para el Empleo adoptado en la $98^{\circ}$ Conferencia Internacional del Trabajo el año 2009 y el extraordinario apoyo logrado en la Conferencia Internacional del año 2011, lo que sirvió de base para la aprobación de la Recomendación $\mathrm{N}^{\circ} 202$, adoptada en la Conferencia celebrada el año siguiente por dicha Organización.

Se señala asimismo que las disposiciones sobre los derechos humanos y las justicia social ${ }^{9}$ entre ellas el derecho a la protección social y a la seguridad social - se han incorporado a las constituciones y a la legislación nacional de la mayoría de los Estados, dentro del contexto de la lucha contra la pobreza extrema, y que diversos estudios sostienen que un paquete básico de protección social que extienda la seguridad de los ingresos y amplíe los servicios de salud esenciales resulta asequible incluso en los países más pobres.

Podría estimarse al efecto que en los países de bajos ingresos, donde prevalecen el empleo informal y el trabajo por cuenta propia, la protección social básica es un primer esfuerzo vital, mientras que en los países de ingresos medios y altos, donde el trabajo asalariado en más común y frecuente, los vínculos podrían orientarse por medio de vínculos formales de seguridad social.

El Piso podría cumplir así un rol de estabilizador social automático, que soporte y ayude a reducir el impacto de las crisis económicas y los desequilibrios mundiales provocados por el elevado nivel de ahorro interno de algunos países en desarrollo, donde la protección social debe acentuarse y no debilitarse.

El Piso busca también combatir la sensación de que la desigualdad de los ingresos y la pobreza aumentan la probabilidad de que se produzcan tensiones y conflictos sociales, y la consiguiente inestabilidad socio política.

\section{LA RECOMENDACIÓN Nº 202, DE 2012, DE LA OIT SOBRE PISO DE PROTECCIÓN SOCIAL}

Este instrumento, adoptado en Ginebra el 14 de junio del año recién pasado, consta de un Preámbulo, en el que se deja constancia la trascendencia que tiene la Seguridad Social para las personas y su desarrollo en todos los planos, como igualmente para los países en que habitan; rememora asimismo los pactos internacionales que la han reconocido.

Luego de ello, señala que, en sus aspectos que estimamos fundamentales que:

a) Se reconoce la responsabilidad general y principal del Estado de aplicar la Recomendación, basada en la universalidad; derecho a las prestaciones y a su adecuación; no discriminación; inclusión social; respeto a los derechos y dignidad de las personas; realización progresiva; solidaridad; diversidad de métodos y enfoques; gestión financiera sostenible, sana, responsable y transparente; coherencia institucional; eficacia y accesibilidad a procedimientos de reclamación; y participación tripartita y celebración de consultas con personas interesadas.

b) Deben establecerse "pisos nacionales de protección social", que incluyan garantías básicas en materia de Seguridad Social, establecidas por ley, debiendo contarse entre estas las relativas a la atención de la salud esencial, sin restricciones por su situación financiera; al

Se cita al efecto la Declaración Universal de los Derechos Humanos, el Pacto Internacional de Derechos Económicos, Sociales y Culturales, la Convención sobre Derechos del Niño, y la Convención sobre la eliminación de todas las forma de discriminación contra la mujer. 
ingreso para los niños, personas en edad activa que no tengan ingresos suficientes y para las personas de edad.

Las aludidas garantías deben alcanzar a todos los residentes del país.

La seguridad del ingreso debe permitir afrontar una vida digna.

Los niveles de las garantías deben ser objeto de revisión periódica, con participación tripartita.

Al otorgarse las garantías deben considerarse diversos enfoques, y cualquier prestación social.

Las prestaciones pueden ser suministradas mediante regímenes universales, de seguro social, de asistencia social, de impuesto negativo sobre la renta, públicos de empleo y de apoyo al mismo.

Deben combinarse medidas preventivas, promocionales, y servicios sociales.

Debe promoverse la actividad económica productiva y el empleo formal.

Debe asegurarse la sostenibilidad financiera, fiscal y económica, tomando en consideración la capacidad contributiva de los distintos grupos de población.

Debe evitarse el fraude, la evasión fiscal y el no pago de las cotizaciones.

c) Contempla un apartado destinado a fijar "Las estrategias nacionales para extender la Seguridad Social", señalando al efecto que:

- Estas deben ser objeto de un Dialogo Social efectivo.

- Considerar que el "piso de protección social" debe ser considerado como un punto de partida para aquellos países que no cuentan con un nivel mínimo de garantías de Seguridad Social.

- Debe tratarse de proporcionar a la mayor cantidad de personas y lo antes posible, niveles de protección más elevados, acordes con la capacidad económica y fiscal de los respectivos países.

- Los países deben establecer en forma progresiva mantener sistemas de Seguridad Social integrales y adecuados, que sean coherentes con los objetivos de las políticas nacionales, procurando articular las políticas de Seguridad Social con las demás políticas públicas.

- Las estrategias deberían aplicarse a las personas que forman parte tanto de la economía formal como de la economía informal, y ser compatible con los planes desarrollo social, económico y medio ambiental.

- Se debe asegurar el apoyo a los grupos desfavorecidos.

- Debería tratarse de alcanzar la gama y niveles de prestaciones establecidos en el Convenio 102 sobre Norma Mínima, y considera la posibilidad de ratificar o de dar efecto a otros Convenios y Recomendaciones de la OIT sobre Seguridad Social que establezcan normas más avanzadas.

d) Finalmente, en materia de "Seguimiento" de la Recomendación. Esta establece que la extensión de la seguridad Social debe procurarse a través de mecanismos apropiados definidos a nivel nacional, organizando consultas tripartitas periódicas, y recogiendo compilando, analizando y publicando regularmente un conjunto apropiado de datos, estadísticas, e indicadores sobre Seguridad Social, tomando en consideración para ello las orientaciones de la OIT, y asegurando la privacidad en sus sistemas de datos.

Como puede observarse, la Recomendación no ha abandonado los criterios y premisas que sustentan al Convenio 102, el que mantiene como un objetivo a conseguir; quizá habría que señalar que dicha línea de acción debería ser objeto de algunas adecuaciones, especialmen- 
te aquellas relativas al financiamiento y gestión del Sistema, cuya evolución nos parece ha sobrepasado los ejes fundantes del aludido instrumento.

De no analizarse dicha opción, nos parece que el aludido Convenio se mantendrá en esta especie de latencia inmovilizadora que no resulta conducente con aprobación y deseas de ejecución.

\section{UNA PROPUESTA}

Nos parece que lo explicitado es posible de sintetizar en algunas posibles alternativas de solución a las situaciones que afectan a las cinco principales ramas del Sistema de Seguridad Social, esto es, la Salud, las Pensiones, la protección de Riesgos Profesionales, la Protección del Desempleo y las Prestaciones familiares, a saber:

a) La cobertura. Siempre ha sido una aspiración del Sistema el ir aumentando la tasa de cobertura; desde la época de Bismarck hasta Beveridge y la evolución posterior ha sido el objetivo principal el que ninguna persona quede al margen del "manto protector" del Sistema. Se han elaborado al efecto diversas estrategias, las que han sido puestas a prueba por el aumento de las crecientes demandas por servicios y beneficios, y los sucesivos cambios macroeconómicos estructurales, siendo el principal desafío actual el de los independientes y los informales. Los primeros siempre habían sido considerados un sector externo, pero los hechos, los porfiados hechos, han demostrado que su crecimiento, crecientemente aumentado por los informales, lo ha constituido en un elemento cuya ausencia provoca graves distorsiones y carencias. Algunos países han optado simplemente por su incorporación obligatoria, como única forma de poner freno al problema, no sin poca resistencia de sus integrantes, pero demostrando en la realidad que la libertad de que gozan no puede ser óbice a que sean objeto de las prestaciones y beneficios del Sistema; de no proceder de dicha forma, sus requerimientos, en definitiva, repercutirían sobre el resto de los integrantes del mismo.

Asimismo, las prestaciones que se otorguen, deben ser adecuadas y entregadas oportunamente; las que no cumplas con dichas condiciones no sirve para solucionar los problemas que aquejan a los afiliados al Sistema.

b) El financiamiento. Este constituye un aspecto crucial para el éxito de todo Sistema de Seguridad Social; si bien otros ejes -como la solidaridad y la confianza pública- le otorgan el basamento social imprescindible, su desarrollo y sustentabilidad están fuertemente vinculados a su sano sostenimiento económico. Si bien durante gran parte de su evolución, el Fondo de Reparto constituyó su común denominador, el desequilibrio demográfico y las sucesivas crisis mundiales demostraron sus falencias y creciente dificultad para sostener el crecimiento del Sistema, a no ser por recortes de beneficios y aumento progresivo y sostenido de tasas de cotizaciones e impuestos generales.

Como alternativa, surgieron los regímenes de Capitalización en Cuentas Individuales, que demostraron su fortaleza en diversos aspectos, sobre todo en el demográfico, pero entraron en contradicción con el principio de la solidaridad.

Ello ha llevado a plantear que la solución más plausible no se encamina por la vía de la sustitución plena del Fondo de Reparto, sino en su complementación por medio de las Cuentas Individuales, lo que permite acceder a una solidaridad atenuada, pero eficaz, y aliviar así al Estado 
y al gasto público de una carga excesiva, que le es imposible mantener por si solo; el esfuerzo individual se traduce así en incentivar a quienes se encuentran en condiciones de hacerlo, para que ahorren una parte de sus ingresos en forma directa y así coadyuvar a generar un régimen que goce de estabilidad financiera permanente.

El rol de la macroeconomía, con sus bases en el ahorro, la inversión y el crecimiento, ha pasado así a tener un papel preponderante en el desarrollo del Sistema; pareciera que una adecuada conjugación de ambos elementos -Reparto y Capitalización Individual - fuere la idea más razonable para obtener su desarrollo más adecuado, y así poder hacer frente a los desafíos demográficos y económicos ya anotados.

Ello permitiría asegurar al Sistema una base de equidad y sostenibilidad, que le es sumamente necesaria.

c) La gestión. Durante gran parte del desarrollo del Sistema, se preconizó que la administración del Sistema debía encontrarse en manos de entes de carácter público, en consonancia con el hecho de que la base de financiamiento era de origen estatal; connotadas excepciones, sobre todo en el ámbito de los riesgos del trabajo y de las prestaciones familiares, permitieron explorar otras alternativas, entregando la administración a entes privados, sin fines de lucro.

La introducción de regímenes de capitalización individual y el surgimiento de la idea de un Estado con un rol subsidiario, abrieron las puertas a una gestión netamente privada, con fines de lucro, pero bajo una fuerte supervisión estatal.

La experiencia tenida a la fecha ha sido de dulce y de agraz; se ha incorporado al Sistema una buena dosis de eficiencia -lo que paulatinamente ha impulsado en el mismo sentido a la gestión pública, a virtud del "efecto de demostración"- pero sin poder evitar que el afán de ganancias excesivas y, en ocasiones, una falta de conocimiento y de convicción sobre los fundamentos del Sistema de Seguridad Social, hayan provocado fuertes cuestionamientos sociales y técnicos a su desempeño.

Pareciera que la vía de solución transita por permitir la coexistencia de ambos sistemas de gestión, pero sujetos a igualdad de condiciones y bajo férreos mecanismos de control que impidan los excesos y desnaturalización de su objeto.

En dicho sentido, debería propenderse a establecer regímenes administrados de un modo seguro, transparente, con costos bajos, y con participación de los interlocutores sociales.

d) La internacionalización. La al parecer inevitable y creciente globalización, ha generado el desafío de hacer frente a fuertes migraciones de trabajadores, tanto en su periodo de actividad como cuando ella ha cesado. Ello obliga a dimensionar soluciones prácticas y factibles en relación al otorgamiento y financiamiento de las prestaciones. Como ya se señaló precedentemente, la Unión Europea abrió un camino sobre el particular, escogiendo la vía de la coordinación, facilitado ello por sus profundos vínculos de todo orden.

Dicha senda parece no ser simple para el resto del orbe, dadas las enormes diferencias que existen entre muchos países; hasta ahora se ha explorado al respecto la suscripción de Tratados Bilaterales (ej. Colombia-Chile) y algunos pocos multilaterales, pero pareciera que ello no basta.

La dificultad estriba, fundamentalmente, en los diversos modelos de financiamiento y gestión que se han ido estableciendo en forma paulatina, siendo nuestro continente latinoamericano una muestra destacable en dicho sentido; es de anotar que la solución requerirá de una fuerte voluntad política que permita superar los escollos anotados, pero la creciente cantidad de migrantes no permite adoptar una posición pasiva sobre la materia. 
Una posible solución al problema lo constituye el establecimiento de una Protección Social Básica Nacional, con soporte estatal, y que, coordinada bajo el amparo de lo preconizado por la OIT, pueda extenderse de un modo Universal.

e) La confianza pública. Los continuos problemas y dificultades por encontrar soluciones adecuadas, han provocado una creciente desconfianza y falta de credibilidad en los resultados del Sistema de Seguridad Social.

Pareciera ser relevante dimensionar adecuadamente en que estriba dicho fenómeno y adoptar medidas tendientes a obtener su adecuado entendimiento y utilización; si no se cuenta con la confianza de los usuarios del Sistema, difícilmente tendrán éxito las medidas de solución que se adopten.

La ciudadanía se ha tornado paulatinamente más y más exigente en obtener soluciones precisas y adecuadas a sus requerimientos de todo orden en esta materia, deseando ser partícipes de las decisiones que sobre el particular se adopten.

Nos parece que el Sistema debería contar con una validación social fuerte, que permita obtener un apoyo masivo en su ejecución, evitando así una falta de respaldo ciudadano, que conspira contra su adecuada ejecución.

La participación en Comités de Usuarios y una progresiva pero fuerte tarea de difusión a todo nivel parecieran ser esenciales en esta materia.

\section{BIBLIOGRAFÍA}

Arenas Monsalve, Gerardo. El Derecho Colombiano de la Seguridad Social. Colombia, Bogotá: Editorial Legis, 2011.

Cortés GonzÁlez, Juan Carlos. Derecho de la Protección Social. Bogotá, Colombia: CIESS, 2009.

Banco de Información de los Sistemas de Seguridad Social Iberoamericanos. Organización Iberoamericana de Seguridad Social. Febrero 2012.

Humeres Noguer, Héctor. El Derecho del Trabajo y de la Seguridad Social.-18 edición-. Santiago, Chile: Editorial Jurídica de Chile, 2013 (en prensa).

Fernández Prol, Francisca. "La Seguridad Social en la Unión Europea”. Ponencia presentada ante el IV Congreso Internacional de Derecho del Trabajo y de la Seguridad Social. Colombia, Bogotá, 2013.

Mendizábal Bermúdez, Gabriela. La Seguridad Social en México en un contexto globalizado. México, D.F.: Editorial Porrúa, 2011.

Piso de Protección Social" Para una Globalización Equitativa e Inclusiva. Informe del Grupo Consultivo presidido por Michelle Bachelet convocado por la OIT con la colaboración de la OMS. OIT. Ginebra. 2011.

Ruiz Moreno, Ángel Guillermo. "Propuestas de solución a la crisis de los sistemas pensionarios en América Latina”, en: García Flores, Francisco y Carrasco Fernández, Felipe (Coords.). El derecho del trabajo y la seguridad social en la globalización. México, D.F.: Editorial Porrúa, 2011.

Ruiz Moreno, Ángel Guillermo. "Futuro de la Seguridad Social en América Latina”. Ponencia presentada ante el IV Congreso Internacional de Derecho del Trabajo y de la Seguridad Social. Colombia, Bogotá, 2013. 